\title{
Duplication of the Gallbladder Associated with Choledocal Cyst: A Case Report
}

\author{
Durim Cela ${ }^{1}$, Besa Hidri ${ }^{1}$, Dorina Aliu ${ }^{1}$ \\ ${ }^{1}$ Service of Imaging, University Hospital Center "Mother Theresa", Tirana, Albania
}

\begin{abstract}
Introduction: Gallbladder duplication is a rare anatomic malformation, which can now be detected by preoperative imaging study. Case presentation: This is a retrospective case report of 39-year-old woman presented during a routine US (ultrasonography) examination complaining intermittent abdominal pain in the upper right quadrant. Laboratory examinations found normal values of total bilirubin, transaminases and alkaline phosphatase. US examination of the right upper quadrant was performed. It was noticed that the gallbladder was duplicated, but there were no distended wall thickening or presence of gallstone. A cystic lesion was noticed that was firstly identified as a pancreatic cyst. The MR cholangiography showed duplicated gallbladder with two cystic ducts and a choledochal cyst. Conclusion: Duplication of the gallbladder is a rare congenital abnormality, which requires special attention to the biliary ductal and arterial anatomy. Laparoscopic cholecystectomy with intraoperative cholangiography seems to be the appropriate treatment.
\end{abstract}

Keywords: duplication of gallbladder, choledocal cyst, ultrasonography. MR cholangiography

\section{Introduction}

Gallbladder duplication is a rare anatomic malformation, which can now be detected by preoperative imaging study. We report a case of an asymptomatic duplicated gallbladder associated with a choledocal cyst. Choledochal cysts represent congenital disproportionate cystic dilatations of the biliary tree. Diagnosis relies on the exclusion of other conditions as a cause of biliary duct dilatation: (i.e. tumour, gallstone or inflammation as the cause).Both anomalies are important to know for surgeons because of associated anatomical variations of main bile duct and hepatic artery and increased risk of common bile duct injury.

\section{Case presentation}

A 39-year-old woman presented during a routine US examination.Physical examination was normal, but the patient has intermittent abdominal pain in the upper right quadrant but the pain was not the reason she performed a US examination. Laboratory examinations found normal values of total bilirubin, transaminases and alkaline phosphatase. US examination of the right upper quadrant was performed (Figure 1). It was noticed that the gallbladder was duplicated, but there were no distended wall thickening or presence of gallstone.A cystic lesion was noticed that was firstly identified as a pancreatic cyst. The MR cholangiography showed duplicated gallbladder with two cystic ducts and a choledochal cyst (Figure 2, 3, 4).Because of no persistent abdominal pain the patient was not hositalized.

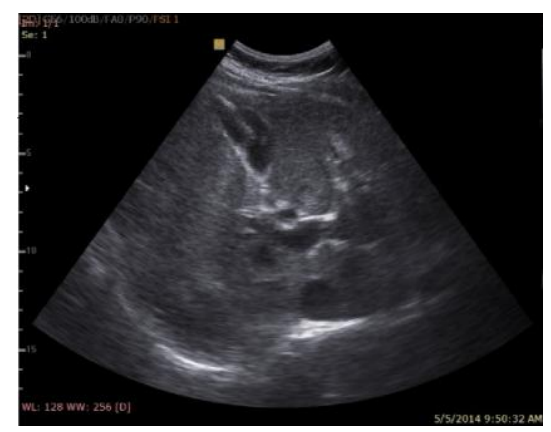

Figure 1: Duplicated gallbladder in Ultrasound

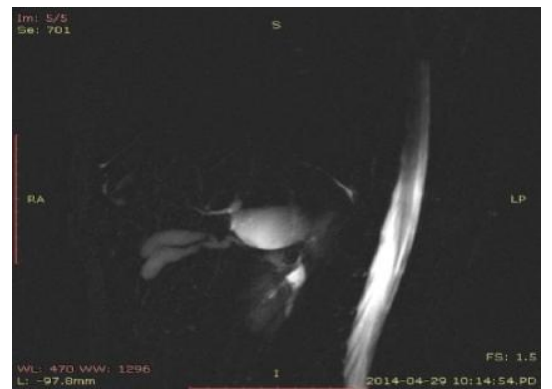

Figure 2: MRCP showing duplicated gallbladder associated with choledocal cyst

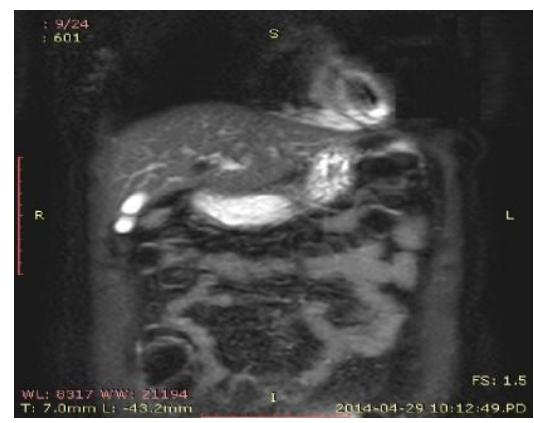

Figure 3: T2W-Spair Coronar MR showing duplicated gallbladder

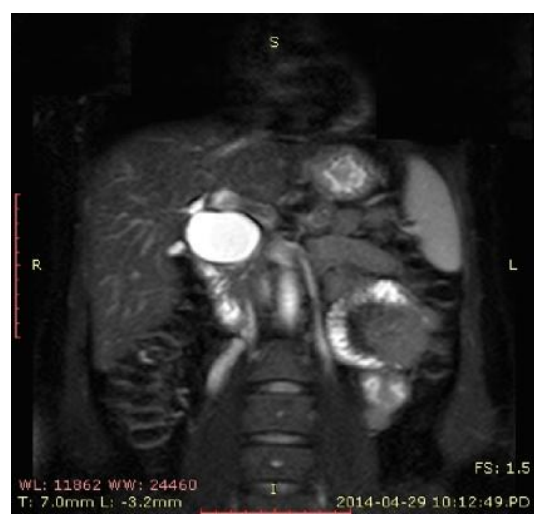

Figure 4: T2W-Spair Coronar MR showing choledocal cyst 


\section{International Journal of Science and Research (IJSR) \\ ISSN (Online): 2319-7064}

Index Copernicus Value (2013): 6.14 | Impact Factor (2014): 5.611

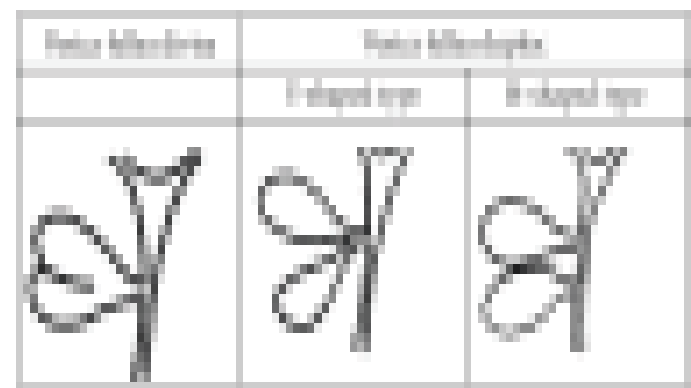

Figure 5: Ggallbladder duplication according to Boyden's classification
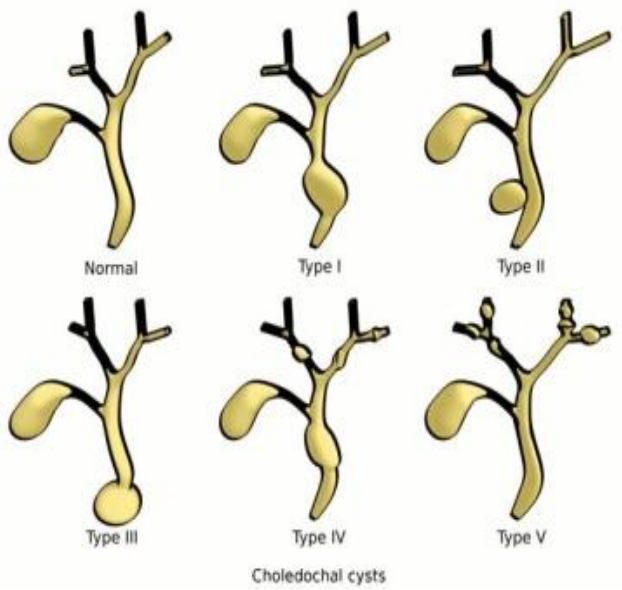

Figure 6: Todani 's Classification of choledocal cyst

\section{Discussion}

Duplication of the gallbladder is a rare congenital anomaly, occurring in about one per 4000 births [1]. It is thought to be due to exuberant budding of the developing biliary tree when the caudal bud of the hepatic diverticulum divides [6, 7].On the other side choledochal cysts are also rare, with an incidence of 1:100000-1500008. [2]. There is no evidence about the incidence of both associated anomalies. The first reported human case of duplication of the gallbladder was noted in a sacrificial victim of Emperor Augustus in $31 \mathrm{BC}$ [5]. This congenital anomaly is important to know for surgeons [5]. Senecail et al. found morphologic variations and abnormalities in more than $33 \%$ but only 3 cases of real duplication from ultrasonographic exploration of the gallbladder performed on 1823 patients [8]. Anatomic variants of gallbladder duplication are still differentiated according to Boyden's classification as follows (Figure 5) [1, 6]:Choledocal cyst classification commonly accepted is one devised by Todani et al (Figure 6), that 5 main types are described.

Boyden's classification of gallbladder duplication.

1. Vesica fellea divisa (bilobed or bifid gallbladder, double gallbladder with a common neck),

2. Vesica fellea duplex (double gallbladder with two cystic ducts), i. Y-shaped type (the two cystic ducts uniting before entering the common bile duct),

ii. H-shaped type (ductular type, the two cystic ducts entering separately into the biliary tree).

Todani's Classification of choledocal cyst

1. Type I - most common, accounting for $80-90 \%{ }^{1}$ (this type can present in utero)

Ia - dilatation of extrahepatic bile duct (entire)

$\mathrm{Ib}$ - dilatation of extrahepatic bile duct (focal segment)

Ic - dilatation of the common bile duct portion of extrahepatic bile duct

2. Type II - true diverticulum from extra hepatic bile duct

3. Type III - dilatation of extra-hepatic bile duct within duodenal wall (choledochocele)

4. Type IV - next most common

IVa - cysts involving both intra and extrahepatic ducts

$\mathrm{IVb}$ - multiple dilatations / cysts of extra hepatic ducts only

5. Type V - multiple dilatations / cysts of intra hepatic ducts only (Caroli disease)

\section{Differential Diagnosis}

Imaging differential considerations include

- gallbladder diverticulum

- gallbladder fold

- Phrygian cap

- choledocal cyst

- focal region of pericholecystic fluid

- focal adenomyomatosis

- intraperitoneal fibrous bands (Ladd bands)

- duodenal diverticulum

- pancreatic cystic lesions

- pseudocyst(s)

- cystic tumours

- other causes of biliary tree dilatation

o impacted gallstone

o cholangiocarcinoma

o biliary stricture

The incidence and nature of clinical problems associated with duplicated gallbladder are similar to those encountered in the single viscus, including acute or chronic cholecystis, cholelithiasis, empyema, torsion, cholecystocolic fistula, lump in the abdomen, and carcinoma. There are no specific symptoms attributable to a double gallbladder. Simultaneaous removal of both gallbladders at surgery is recommended to avoid cholecystis and symptomatic gallstones in the remaining organ [3, 9]. Several publications reported successful laparoscopic cholecystectomy for a duplicate gallbladder [3, 4, 9-17].Schroeder and Draper reported a successful laparoscopic cholecystectomy for a tripe gallbladder [18]. Because there does not seem to be a significantly increased risk for subsequent disease, prophylactic cholecystectomy in an asymptomatic patient with gallbladder duplication is not recommended [3]. It could now be detected preoperatively by imaging studies. US is generally the first choice of imaging modality in patients with suspected biliary disease. US may diagnose gallbladder 


\section{International Journal of Science and Research (IJSR) \\ ISSN (Online): 2319-7064}

Index Copernicus Value (2013): 6.14 | Impact Factor (2014): 5.611

duplication if the viscera are located separately. Some criteria have been defined to diagnose gallbladder duplication on US examination in limited case reports [19-22]. Although US findings may suggest a double gallbladder, the cystic duct is usually not identified.In our case it was suggested by US it might be a cystic lesions of pancreas. Duplication should be considered when two cystic ducts are present on preoperative imaging. MR Cholangiography proved to be a valid, noninvasive imaging technique for the evaluation of patients with suspected anomalies of the gallbladder after initial scanning with US [23]. Helical CT scan can also be helpful [22]. Duplication of the gallbladder has been detected by oral cholecystography, scintigraphy, and percutaneous transhepatic cholangiography but these examinations are not routinely used in patients with biliary disease [23]. Concomitance with other congenital anomalies, such as an anomalous right hepatic artery, has been described and may lead to intraoperative injury [5]. Attention is being focused on the need of complete evaluation during surgery by intraoperative cholangiography to prevent inadvertent injury to the biliary system [3].

\section{Conclusion}

Duplication of the gallbladder is a rare congenital abnormality, which requires special attention to the biliary ductal and arterial anatomy. Laparoscopic cholecystectomy with intraoperative cholangiography seems to be the appropriate treatment.

\section{References}

[1] E. A. Boyden, - The accessory gallbladder: an embryological and comparative study of aberrant biliary vesicles occuring in man and the domestic mammals," American Journal of Anatomy, vol. 38, pp. 177-231, 1926.

[2] Kim OH, Chung HJ, Choi BG. Imaging of the choledochal cyst. Radiographics. 1995;15 (1): 69-88.

[3] J.-F. Gigot, B. Van Beers, L. Goncette, et al., - -hparoscopic treatment of gallbladder duplication: a plea for removal of both gallbladders," Surgical Endoscopy, vol. 11, no. 5, pp. 479-482, 1997.

[4] F. Borghi, G. Giraudo, P. Geretto, and L. Ghezzo, -Pefioration of missed double gallbladder after primary laparoscopic cholecystectomy: endoscopic and laparoscopic management, " Journal of Laparoendoscopic and Advanced Surgical Techniques, vol. 18, no. 3, pp. 429-431, 2008.

[5] R. Udelsman and P. H. Sugarbaker, -Cngenital duplication of the gallbladder associated with an anomalous right hepatic artery," American Journal of Surgery, vol. 149, no. 6, pp. 812-815, 1985.

[6] M. Lamah, N. D. Karanjia, and G. H. Dickson, -Antomical variations of the extrahepatic biliary tree: review of the world literature," Clinical Anatomy, vol. 14, no. 3, pp. 167172,2001

[7] P. R. Kothari, T. Kumar, A. Jiwane, S. Paul, R. Kutumbale, and B. Kulkarni, -Unsual features of gall bladder duplication cyst with review of the literature, "Pediatric Surgery International, vol. 21, no. 7, pp. 552-554, 2005.

[8] B. Senecail, F. Texier, I. Kergastel, and L. Patin-Philippe, -Antomic variability and congenital anomalies of the gallbladder: ultrasonographic study of 1823 patients," Morphologie, vol. 84, no. 264, pp. 35-39, 2000.
[9] M. C. Horattas, -Gallhdder duplication and laparoscopic management, " Journal of Laparoendoscopic and Advanced Surgical Techniques A, vol. 8, no. 4, pp. 231-235, 1998.

[10] S. Nakashima, K. Fukuda, O. Kinoshita, H. Nagata, A. Furutani, and M. Masuyama, -Cas of laparoscopic cholecystectomy for a double gallbladder, "Nippon Shokakibyo Gakkai Zasshi, vol. 106, no. 1, pp. 91-97, 2009.

[11] T. Z. Nursal, S. Ulusan, F. Tercan, et al., - -aparoscopic management of gallbladder duplication," International Surgery, vol. 92, no. 4, pp. 195-197, 2007.

[12] M. Pitiakoudis, N. Papanas, A. Polychronidis, E. Maltezos, P. Prassopoulos, and C. Simopoulos, -Doble gallbladder-two pathologies: a case report, " Acta Chirurgica Belgica, vol. 108, no. 2, pp. 261-263, 2008.

[13] J. M. Maddox and M. L. Demers, - -aparoscopic management of gallbladder duplication: a case report and review of literature, " Journal of the Society of Laparoendoscopic Surgeons, vol. 3, no. 2, pp. 137-140, 1999.

[14] R. D. Cummiskey and L. P. Champagne, -Dplicate gallbladder during laparoscopic cholecystectomy," Surgical Laparoscopy, Endoscopy and Percutaneous Techniques, vol. 7, no. 3, pp. 268-270, 1997.

[15] A. Goel, K. N. Srivastava, and A. K. Rana, -Doble gallbladder - a laparoscopic management," Surgical Laparoscopy, Endoscopy and Percutaneous Techniques, vol. 13, no. 5, pp. 348-349, 2003.

[16] A. Sasaki, T. Yoshida, K. Kakisako, M. Ohta, K. Shimoda, and S. Kitano, - hparoscopic cholecystectomy for a double gallbladder of the duodenal type, " Surgical Laparoscopy, Endoscopy and Percutaneous Techniques, vol. 15, no. 6, pp. 355-358, 2005.

[17] K. Shirahane, K. Yamaguchi, T. Ogawa, et al., —Gallłdder duplication successfully removed laparoscopically using endoscopic nasobiliary tube, " Surgical Endoscopy, vol. 17, no. 7, p. 1156, 2003.

[18] C. Schroeder and K. R. Draper, -hparoscopic cholecystectomy for triple gallbladder," Surgical Endoscopy, vol. 17, no. 8, pp. 1322-1325, 2003.

[19] K. L. McDonald and T. Lwin, -Snographic and scintigraphic evaluation of gallbladder duplication," Clinical Nuclear Medicine, vol. 11, no. 10, pp. 692-693, 1986.

[20] M. J. Diaz, W. Fowler, and B. J. Hnatow, -Cngenital gallbladder duplication: preoperative diagnosis by ultrasonography," Gastrointestinal Radiology, vol. 16, no. 3, pp. 198-200, 1991.

[21] R. C. Goiney, S. A. Schoenecker, D. R. Cyr, W. P. Shuman, M. J. Peters, and P. L. Cooperberg, - Snography of gallbladder duplication and differential considerations," American Journal of Roentgenology, vol. 145, no. 2, pp. 241-243, 1985.

[22] A. Ozgen, D. Akata, A. Arat, F. B. Demirkazik, M. N. Ozmen, and O. Akhan, -Gallladder duplication: imaging findings and differential considerations," Abdominal Imaging, vol. 24, no. 3, pp. 285-288, 1999.

[23] S. Mazziotti, F. Minutoli, A. Blandino, S. Vinci, I. Salamone, and M. Gaeta, -Gallbdder duplication: MR cholangiography demonstration," Abdominal Imaging, vol. 26, no. 3, pp. 287-289, 2001 